\title{
BMJ Open Does smoke-free legislation work for teens too? A logistic regression analysis of smoking prevalence and gender among 16 years old in Ireland, using the 1995-2015 ESPAD school surveys
}

Shasha Li, Sheila Keogan, Luke Clancy

To cite: Li S, Keogan S, Clancy L. Does smoke-free legislation work for teens too? A logistic regression analysis of smoking prevalence and gender among 16 years old in Ireland, using the 1995-2015 ESPAD school surveys. BMJ Open 2020;10:e032630. doi:10.1136/ bmjopen-2019-032630

- Prepublication history and additional material for this paper are available online. To view these files, please visit the journal online (http://dx.doi. org/10.1136/bmjopen-2019032630).

Received 28 June 2019 Revised 27 February 2020 Accepted 21 April 2020
D) Check for updates

(c) Author(s) (or their employer(s)) 2020. Re-use permitted under CC BY-NC. No commercial re-use. See rights and permissions. Published by BMJ.

TU Dublin, TobaccoFree Research Institute Ireland, Kevin Street, Dublin 8, Dublin, Ireland

Correspondence to Professor Luke Clancy; Iclancy@tri.ie

\section{ABSTRACT}

Objectives To assess the role of tobacco control legislation (TCL) in youth smoking in Ireland. To examine the effects of smoke-free legislation in youth. To consider whether TCL contributed to the gender equalisation in prevalence in 16 years old seen between 2003 and 2015. Setting Data are from the 4 yearly European School Survey Project on Alcohol and Other Drugs from 1995 to 2015. Total sample size was 12.394. A logistic regression model on grouped data was used. Dependent variable is whether a student was a smoker in last 30 days. Independent variables are time, gender and the policy indicators, workplace ban on smoking, point-of-sale (POS) display ban, the introduction of graphical images on packs and the average real price of cigarettes.

Results Smoking prevalence dropped from 41\% in 1995 to $13 \%$ in 2015. The effects of policies differed between boys and girls. For girls, estimates for workplace bans, graphical images on packs and a unit real (Consumer Price Index adjusted) price increase reduced prevalence by $7.31 \%(95 \% \mathrm{Cl} 2.94 \%$ to $11.68 \%), 8.80 \%$ (95\% Cl $2.60 \%$ to $15.01 \%)$ and 5.87 (95\% Cl 2.96 to 8.79$)$, respectively. The POS ban did not have a significant effect in girls. For boys, estimates for workplace bans and a unit real price increase, reduced prevalence by $8.41 \%(95 \% \mathrm{Cl}$ $5.16 \%$ to $11.66 \%$ ) and $4.93 \%$ (95\% Cl $0.77 \%$ to $9.08 \%)$, respectively, POS gave an increase of $7.02 \%(95 \% \mathrm{Cl}$ $1.96 \%$ to $12.40 \%$ ). The introduction of graphical images had an insignificant effect.

Conclusions TC legislation helps to explain the outof-trend reduction in youth smoking prevalence. The estimated differential effects of the workplace ban, POS displays, real price changes and graphical images on packs help to explain the sharper decline in girls than boys. These findings should remind policy-makers to give increased consideration to the possible effects on young people of any legislative changes aimed at adults in TCL.

\section{INTRODUCTION}

Ireland is one of the pioneer countries in tobacco control and is consistently near, or at, the top of the European Tobacco Control Scale which is based on the number and type of TC interventions and completeness of
Strengths and limitations of this study

- The European School Survey Project on Alcohol and Other Drugs (ESPAD) survey provides the best available adolescent data on smoking prevalence in Ireland from 1995 to 2015

- Nevertheless, the sample size is not ideally large and the interval between surveys is long at 4 years.

- The number of male and female smokers for the years 1999 and 2003 was calculated using published ESPAD Ireland data on prevalence and total sample size.

- Most of the important tobacco control legislation in Ireland occurred during period 1995-2015 and their contribution to the reduction in prevalence in adolescent smoking is examined.

their implementation. ${ }^{1}$ The harmful effects of secondhand smoke had become well known since the 1980s and bans on smoking in the workplace had been introduced by many communities and some states particularly in the USA.

Smoking in workplaces was banned in Ireland on a comprehensive national basis on the 29 March 2004, making Ireland the first country in the world to institute a comprehensive national ban on smoking in workplaces. From that date onwards, under the Public Health (Tobacco) Acts 2002, it has been illegal to smoke in all enclosed workplaces, including bars, restaurants, clubs, offices, public buildings and schools. The bans are strictly enforced. $^{2}$ While the 2004 smokefree workplaces legislation has reduced adult smoking prevalence ${ }^{34}$ and helped to avoid at least 3500 tobacco-related deaths in Ireland in the first 3 years, ${ }^{5}$ its impact on adolescents is less clear.

A particularly large reduction, especially in girls, was observed in Irish adolescent smoking 
prevalence between 2003 and 2015. Smoking in Irish girls exceeded that in boys for the 20 years preceding the introduction of strong tobacco control measures beginning in 2002. This high prevalence in girls was not unique in Europe but occurs in the context of the highest level of adult female smoking, reported in the world, being in WHO Euro region. ${ }^{6}$

In Ireland, prevalence fell from $44.9 \%$ in 1995 to $13.1 \%$ in 2015 in girls and from $36.7 \%$ to $13.1 \%$ in boys. ${ }^{7}$ There were no school-specific tobacco control legislation (TCL) introduced between 1995 and 2015. However, Smoke-free legislation (2004) and other policies that could potentially help to reduce adolescent smoking prevalence were introduced since 1995. These were (1) a ban on packs of 10 cigarettes at the end of May 2007, (2) the point-of-sale (POS) advertising display ban of tobacco products introduced in 2009 and (3) the inclusion of graphical images on both sides of tobacco packs in 2011 (online supplementary appendix 1).The existing international evidence suggested that these interventions could be expected to advance tobacco control and help to reduce smoking in young people. ${ }^{8-10}$

In particular, Ireland was the first country in European Union (EU) to implement a ban on POS display, which came into effect on 1 July 2009. The legislation prohibited advertising of tobacco products in retail premises and mandated that tobacco products must be stored out of view of customers. It also prohibited vending machines except in licensed premises and registered clubs (in accordance with Regulations), and that all persons selling tobacco products by retail had to register with the Office of Tobacco Control. One of the motivations behind these legislative changes was to reduce awareness of smoking, especially among young people.

This study sets out to assess if smoke-free legislation, which was not targeting adolescents, was effective in reducing adolescent smoking in Ireland, and to see if it could help to explain the large fall in 30-day smoking prevalence, particularly in girls, occurring in recent years. Also, to consider whether the other TC measures, which are described above, contributed to the gender equalisation in prevalence in 16 years old that occurred between 2003 and 2015.

\section{METHODS \\ Data}

This study used data from the European School Survey Project on Alcohol and Other Drugs (ESPAD) in Ireland. The main purpose of the survey was to collect comparable data on substance use among 16-year-old students across Europe, in order to monitor trends within and between countries, including Ireland. ${ }^{8}$ ESPAD surveys were conducted every 4 years from 1995 to 2015, resulting in six waves of data from 26 countries, and 35 countries participating in 2015.The sampling procedures, data collection and questionnaires used in Ireland were consistent with the international ESPAD study protocol. ${ }^{8}$ School
Table 1 Reconstructed number of smokers from six ESPAD surveys from 1995 to 2015

\begin{tabular}{lllll}
\hline & $\begin{array}{l}\text { Male } \\
\text { smokers }\end{array}$ & $\begin{array}{l}\text { Female } \\
\text { smokers }\end{array}$ & $\begin{array}{l}\text { Total } \\
\text { smokers }\end{array}$ & $\begin{array}{l}\text { Total survey } \\
\text { sample }\end{array}$ \\
\hline 1995 & 328 & 421 & 749 & 1832 \\
1999 & 355 & 491 & 846 & 2277 \\
2003 & 343 & 442 & 785 & 2407 \\
2007 & 194 & 325 & 519 & 2216 \\
2011 & 207 & 254 & 461 & 2205 \\
2015 & 98 & 92 & 190 & 1467 \\
\hline
\end{tabular}

ESPAD, European School Survey Project on Alcohol and Other Drugs.

students born in specific calendar years were eligible and selected in Ireland using stratified random sampling.

Data were collected anonymously through paper-andpencil, self-completion questionnaire administered in the classroom. After standardised cleaning procedures, the datasets (2007, 2011 and 2015 waves) were obtained from the ESPAD official database. Full accounts of the methodology of the study in each survey year can be found in the respective reports of the ESPAD project. ${ }^{8-10}$

Original raw datasets from the 1999 and 2003 waves were unavailable. However, smoking prevalence and sample size of both genders are available from officially published reports. ${ }^{11} 12$ The number of smokers and nonsmokers of both genders in those two surveys are reconstructed as shown in table 1 .

The final data were aggregated every 4years from 1995 to 2015 , with an average of 2067 observations per survey year. The observed smoking prevalence estimates as the average of $0-1$ smoker variable that indicates whether an individual in the sample smokes. The prevalences along the years are shown in figure 1 . Tobacco control policies which may have confounded the impact of workplace ban on adolescent smoking are included in the model. In particular, indicator variables for the introduction of the POS ban and graphical images shown on packages were included.

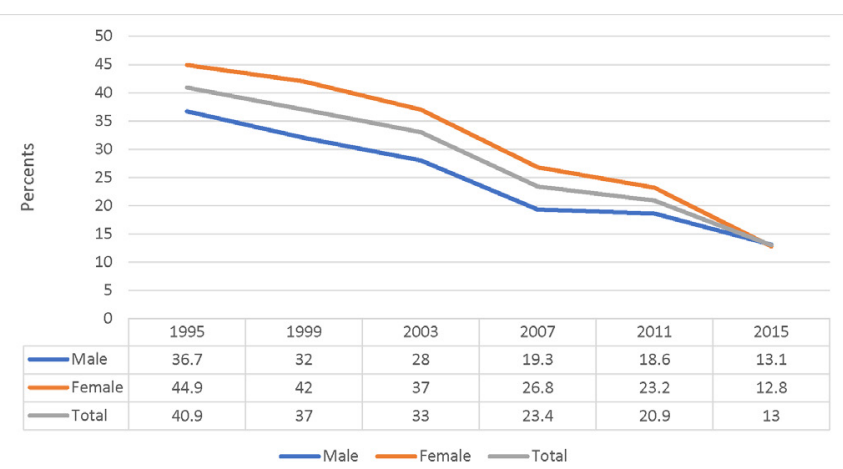

Figure 1 Trend of Irish adolescent smoking prevalence by gender (\%) 1995-2015 ESPAD surveys. ESPAD, European School Survey Project on Alcohol and Other Drugs. 
Increasing price on cigarettes is found to be one of the most effective measures in reducing smoking, particularly among adolescents as they usually have less disposable money and cigarettes are therefore less affordable for them than they are for adults. ${ }^{13}{ }^{14}$ Ireland has increased the price of cigarettes every year since 1995 , from $€ 3.5$ in 1995 to $€ 10.5$ in 2015 .

The real price changes, where price is adjusted for Consumer Price Index, are shown in the online supplementary file 1 . We used changes in real price, rather than changes in tobacco taxes, because of the industry and retailers' roles in pricing of tobacco products may distort the effects of taxation. ${ }^{15}$

Average real price, therefore, is included in the model to capture price effect.

\section{Statistical analysis}

Seven models are assessed. First, we look at the impact of real price on adolescent prevalence (model 0 ). Then we assess the impact of workplace ban on adolescent smoking by adding a workplace ban indicator, together with price (model 1). Then we repeat the first step by replacing the workplace ban by the POS ban indicator (model 2) and graphical images indicator (model 3). Pairwise combinations of the policy indicators are also considered (models 4-6). Lastly, all policy indicators and price are included (model 7). Various criteria are used to determine the best model. In particular, models with smaller Akaike information criterion (AIC) values and Bayesian information criterion values are preferred. Likelihood ratio tests are used for comparing two nested models. A significant test suggests that the full model is an improvement on the reduced model.

All analyses were performed with the Stata V.13 (StataCorp)

We show the main results from logistic regressions on grouped data separately for boys and girls (online supplementary file 2).

\section{Patient and public involvement}

No patient involved.

\section{RESULTS}

The regression results of the seven models are presented in online supplementary file 2 . For boys, all of the variables in each model are strongly significant except for graphic images. Average real price increase and introducing the workplace ban reduced smoking prevalence. Model 4 provides the best fit to the data as shown in table 2A. First, model 4 has the smallest AIC among the seven models. Second, the likelihood ratio tests on model 4 and model $0-2$ are all significant (all $\mathrm{p}<0.02$ ), which implies that model 3 is an improvement on the reduced models. In addition, likelihood ratio test on model 4 and model 7 is insignificant ( $\mathrm{p}=0.81$ ), which shows that model 7 is not an improvement on model 4. It is confirmed by the insignificant coefficient of graphical images in model 7.
Table 2A ESPAD 1995-2015 Logistic regression results from best fit models

\begin{tabular}{lll}
\hline \multirow{2}{*}{ Variables } & \multicolumn{2}{l}{ Regression results (Odds ratios and $\mathbf{C l})$} \\
\cline { 2 - 3 } Real price & $\begin{array}{l}0.63^{\star \star \star} \\
(0.52 \text { to } 0.75)\end{array}$ & $\begin{array}{l}0.75^{\star \star \star} \\
(0.65 \text { to } 0.86)\end{array}$ \\
\hline Workplace ban & $\begin{array}{l}0.76^{\star} \\
(0.60 \text { to } 0.96)\end{array}$ & $\begin{array}{l}0.70^{\star \star} \\
(0.56 \text { to } 0.86)\end{array}$ \\
\hline POS ban & $1.48^{\star}$ & \\
\hline Graphic images & $(1.10$ to 2.00$)$ & \\
& & $0.65^{\star \star}$ \\
Constant & $2.83^{\star \star}$ & $(0.47$ to 0.88$)$ \\
Observations & 6080 & $2.13^{\star \star}$ \\
AIC & 6657 & $(1.22$ to 3.72$)$ \\
BIC & 6684 & 6324 \\
\hline
\end{tabular}

${ }^{* * *} \mathrm{P}<0.001,{ }^{* *} \mathrm{p}<0.01,{ }^{*} \mathrm{p}<0.05$.

Table 2B shows how much the boys' prevalence was marginally affected by various variables in the best fit model, that is, model 4. Controlling for price and POS ban, introducing the workplace ban reduced the prevalence by $4.93 \%$ (95\% CI $0.77 \%$ to $9.08 \%$ ), which is a considerable reduction given the prevalence before the ban was $33 \%$. The effect of real price increase is also large and significant, with a unit increase in the real price could reduce the prevalence by $8.41 \%$ (95\% CI $5.16 \%$ to $11.66 \%)$. However, POS ban was associated with increased prevalence by $7.02 \%$ (95\% CI $1.65 \%$ to $12.40 \%$ ).

For girls, model 5 provides the best fit as shown in table 2. First, the likelihood ratio tests on model 5 and model 0,1 and 3 are all significant $(p<0.01)$, suggesting that model 5 is an improvement on the reduced models. In addition, likelihood ratio test on models 5 and 7 is insignificant $(\mathrm{p}=0.20)$. Model 7 is not an improvement on model 5 , confirmed by the insignificant coefficient of POS ban. Second, model 5 has smallest AIC.

From table 2B, we can see that introducing the workplace ban reduced girls' prevalence by $7.31 \%$ (95\% CI $2.94 \%$ to $11.68 \%$ ), which is larger than the effect on boys, but without statistically significant difference. In addition, the marginal effect of real price is $5.87 \%$ (95\% CI $2.96 \%$ to $8.79 \%$ ), which is smaller than the price effect on boys. Introduction of graphical images is associated with $8.80 \%$ (95\% CI $2.60 \%$ to $15.01 \%$ ) reduction in girls' prevalence, in contrast to the insignificant impact on boys.

The best fit models for boys and girls match the actual prevalence, of smoking from the ESPAD surveys from 1995 to 2015 , well (figure 2).

\section{DISCUSSION}

Although there is a general decline in adolescent smoking prevalence in ESPAD countries, there is no evidence of 
Table 2B ESPAD 1995-2015 Reduction in smoking prevalence from best fit models

\begin{tabular}{lll}
\hline \multirow{2}{*}{ Variables } & \multicolumn{2}{l}{ Marginal effect (Reduction in prevalence and Cl) } \\
\cline { 2 - 3 } Rey & Girl \\
\hline Real price & $-8.41 \% \%^{* \star *}$ & $-5.87 \%$ *** \\
& $(-11.66 \%$ to $-5.16 \%)$ & $(-8.79 \%$ to $-2.96 \%)$ \\
Workplace & $-4.93 \%^{*}$ & $-7.31 \% \%^{* *}$ \\
ban & $(-9.08 \%$ to $-0.77 \%)$ & $(-11.68 \%$ to $-2.94 \%)$ \\
POS ban & $7.02 \% *$ & \\
Graphic & $(1.65 \%$ to $12.40 \%)$ & \\
images & & $-8.80 \%{ }^{* *}$ \\
\hline
\end{tabular}

${ }^{* * *} \mathrm{P}<0.001,{ }^{* *} \mathrm{p}<0.01,{ }^{*} \mathrm{p}<0.05$

AIC, Akaike information criterion; BIC, Bayesian information criterion; ESPAD, European School Survey Project on Alcohol and Other Drugs POS, point of sale.

convergence in the different countries or geographical regions. ${ }^{16}$ In Ireland, there was a steep drop in adolescent smoking prevalence between 2003 and 2007 when the decline was similar in girls and boys but greater in girls. The results show that the workplace ban introduced in 2004 helps to explain the steep drop in prevalence when controlling for the real price effect, which itself is consistently found to be effective in other studies. ${ }^{17}{ }^{18}$ In particular, although the overall average real price increased for the 2003-2007 period compared with the previous period, the annual real price actually decreased for the 2 years, 2005 and 2006. This reinforces the strong impact of the workplace ban on reducing smoking prevalence between the 2003 and 2007 period. In addition, the workplace ban rendered an estimated additional 5\% reduction in actual smoking prevalence beyond price effect, which is a considerable effect given that the prevalence was $37 \%$ among females and 28\% among males in 2003. The study, however, also confirms that real cigarette prices are strong determinants of youth smoking. ${ }^{1718}$

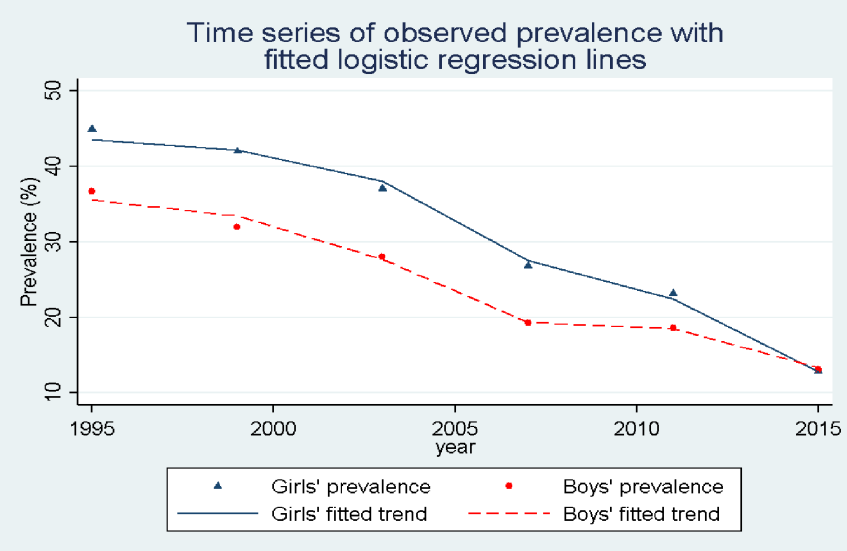

Figure 2 Prevalence of smoking from ESPAD surveys from 1995 to 2015 and fitted lines of predicted prevalence from best fit models for boys and girls. ESPAD, European School Survey Project on Alcohol and Other Drugs.
The other components of the WHO MPOWER policy package, consisting of a series of technical measures and resources to assist country-level implementation of the WHO Framework Convention on Tobacco Control, for example, smoking cessation services, advertising, promotion and sponsorship, did not change significantly between 2003 and 2007. In particular, mass media campaigns stayed moderately funded for the whole period of 1995-2015. Health warnings were moderate between 2003 and 2007, and cessation treatment and youth access were stable in the period. ${ }^{19}$ Therefore, between 2003 and 2007, the only significant and positive change in tobacco control policies was the introduction of workplace ban.

The mechanisms that explain the link between the workplace ban and adolescent smoking prevalence are uncertain and our data do not allow a further interrogation. However, some studies from other countries have provided some explanations..$^{20}$ For example, one study shows that stronger public places restrictions had a significantly protective effect on smoking prevalence..$^{21}$ Another suggested that a workplace ban affects adolescents who are at work (through part-time jobs). ${ }^{22}$ It showed that adolescents who worked in smoke-free workplaces were only $68 \%$ (95\% CI $51 \%$ to $90 \%$ ) as likely to be smokers as adolescents who worked in a workplace with no smoking restrictions. It is also possible that the discourse around smoking which occurred preimplementation of smokefree legislation helped to denormalise smoking in general even though the law was primarily about the workplace. ${ }^{23}$ The decrease in prevalence from 2007 to 2011 was much steeper in girls than boys.

During this period, the annual real price decreased from 2010 to 2011 although the average real price for the period 2007 to 2011 increased slightly (online supplementary file 1). The model suggests that price has a greater marginal effect on boys than girls $(8.4 \%$ vs $5.8 \%)$. The decrease in the annual real price, which is not taken into account in the change of average real price in the model and the finding that the workplace ban seemed to have a greater effect in girls than boys $(7.3 \%$ vs $4.9 \%)$ may partially explain the difference in the rate of decline of prevalence.

The impact of the POS ban on reducing youth smoking prevalence was not significant, which is consistent with the finding of the study by McNeill. et al. ${ }^{24}$ They failed to find significant short-term changes in prevalence among youths or adults due to POS ban. However, their study showed that the proportion of youths believing that more than a fifth of children their own age smoked decreased from $62 \%$ to $46 \%, \mathrm{p}<0.001)$. Postlegislation, $38 \%$ of teenagers thought it would make it easier for children not to smoke. Compliance was very high and the law was well supported. Recall of tobacco displays among teenagers reduced significantly postlegislation and there were encouraging signs that the law helped denormalise smoking. While it was postulated at the time that it might take a longer time for the POS ban to effectively reduce smoking prevalence among youths, 
we have not seen it in this study based on a longer time series. Others, however, have seen more positive results in young people. ${ }^{25} 26$

Context may be significant in this regard as our population were under age for legal purchase of cigarettes in Ireland and access in those circumstances occurs through other routes where POS displays may not be relevant. It does not however explain why the POS display ban was associated with a negative effect in boys in this analysis. It seems likely that this may have been partially a price effect because the real price actually declined in two of the relevant years (online supplementary file 1) 2005 and 2006 but also there was a marked switch to cheaper roll your own cigarettes in both adults and teens. ${ }^{27} 28$

In ESPAD countries, with different initial status from Ireland, generally, gender convergence is marked in smoking prevalence. In 1995, on average in ESPAD countries boys showed higher smoking prevalence than girls. In 2015, these differences were no longer apparent or became smaller. However, in 1995 Irish female adolescents had a much higher smoking prevalence than male adolescents ( $45 \%$ vs $37 \%$ ), price and workplace ban effects were marked in both genders but somewhat different. As discussed above price effect was stronger in boys than girls although there is no conclusive evidence on this in the literature. ${ }^{17} 28$ The impact of the POS ban differed between the two groups. In particular, POS ban did not significantly affect girls' smoking prevalence, while it is significantly and positively (7 \%) related to boys' smoking prevalence.

The introduction of graphical images on packs seemed to have a much greater impact on girls with an $8.8 \%$ marginal effect whereas it had no significant effect on boys. These differential effects on POS and graphical images with the lesser differentials for price and the workplace ban may explain why we observed that by the end of the period, the gender gap was closed, with female prevalence being less than male prevalence by 2015 , consistent with most ESPAD countries.

One of the potential issues of the above analysis is that the sample size is not ideally large and the interval between each survey is long, as there were only six surveys between 1995 and 2015. However, this is so far the best adolescent survey data in Ireland that provides adolescent smoking prevalence. Other surveys on smoking either did not have enough adolescent samples (eg, Survey on Lifestyle and Attitude to Nutrition and Healthy Ireland surveys), or were too recent to establish a baseline before the policies were introduced (eg, Monthly phone interview surveys from National Tobacco Control Office from 2002), or had fewer data points (eg, Health Behaviour in School-aged Children study had 5 waves between 1998 and 2014). Another limitation is that the data of 1999 and 2003 were obtained by recalculating the number of male and female smokers based on prevalence and total sample size, a process which may have introduced very small inaccuracies. However, the results are clear cut and the margin of error compared with total sample is negligible. Therefore, the process should not have significant impact on the results.

\section{CONCLUSIONS}

Adolescent smoking prevalence dropped significantly in boys and girls in Ireland. This study found that the workplace ban introduced in 2004, to protect workers and customers from secondhand smoking, has significantly helped to explain the out-of-trend reduction in adolescent smoking prevalence. While removal of POS tobacco promotion may have reduced awareness of smoking among young people, there was no evidence of a beneficial effect on prevalence. Graphic images appear to have made a significant impact on girls' smoking prevalence but not on boys. In addition, we confirmed that price increase was consistently effective in both boys and girls. The implications for the whole population, considering age and gender, should be considered for all TCLs being introduced by policy-makers irrespective of the targeted segment of the population.

Contributors LC conceived the study. LC and SL designed the study. SL, SK and LC were involved in analysis of the data. SL drafted the first version of the manuscript. LC and SK had input into all redrafts. All authors read and approved the final version.

Funding Department of Health Ireland RFT: DOH RFT ESPAD 2015. Royal City of Dublin Hospital Trust: RCDHT grant 178.

Disclaimer The funders of the study had no role in study design, data collection, data analysis, data interpretation, or writing of the report. The corresponding author had full access to all the data in the study and had final responsibility for the decision to submit for publication.

Patient consent for publication Not required.

Ethics approval Ethical approval was awarded by Dublin Institute of Technology, Research Ethics, Ethical Clearance Ref $18-126$. New approval for this use of the study data set was not considered necessary as ESPAD Ireland PI with full access to ESPAD data set. We used fully anonymised aggregate data.

Provenance and peer review Not commissioned; externally peer reviewed.

Data availability statement No data are available. No additional data availableThe data were from the European School SurveyProject on Alcohol and Other Drugs (ESPAD) and various official reportsavailable from http://www.espad.org/ reportsdocuments. With the 2003 datacollection as a starting point, it was decided that all country datasets should bemerged into a common database. After that also data from 2007 and 2011 areavailable in separate databases. Initially, these databases were stored andmaintained by the Databank Manager Thoroddur Bjarnson. During the 2015wave of ESPAD, the international database was compiled and standardised byCAN (Stockholm). Even though, since 2007, countries are obliged to delivertheir national datasets to the database, there are-as stated in the databaserules-no obligations to let other researchers use the national data withoutpermission. In order to obtain a copy of a database, an application form has tobe filled in and posted to the coordinators for further distribution to the ESPADApplication Committee. The composition of the committee as well asrestrictions around the database and its use are described and explained in theESPAD database rules (database rules for ESPAD researchers and databaserules for non-ESPAD researchers). When an application is approved, a contractis signed before a copy of the database is delivered. Approved applications arepresented in a list, which also displays the deadline of the projects. ESPADresearchers are allowed to apply for the most recent database once thelnternational ESPAD Report has been released. Non-ESPAD researchers arealso allowed to work with ESPAD data. Access for nonESPAD researchers isallowed after an embargo period determined by an assembly: ESPAD 2003Database: accessible now. ESPAD 2007 Database: was accessible since 1 July2013. ESPAD 2011 Database: was accessible since 1 July 2015. ESPAD 2015Database: at present, it is only accessible to ESPAD researchers. http://www. espad.org/sites/espad.org/themes/cs_espad/logo.pngg. 
Open access This is an open access article distributed in accordance with the Creative Commons Attribution Non Commercial (CC BY-NC 4.0) license, which permits others to distribute, remix, adapt, build upon this work non-commercially, and license their derivative works on different terms, provided the original work is properly cited, appropriate credit is given, any changes made indicated, and the use is non-commercial. See: http://creativecommons.org/licenses/by-nc/4.0/.

ORCID iD

Luke Clancy http://orcid.org/0000-0003-2407-2263

\section{REFERENCES}

1 Joossens L, Raw M. The tobacco control scale 2016 in Europe. Brussels: European cancer League associations, 2016. https://www. tobaccocontrolscale.org/2016-edition/

2 Irish Government. Public health (tobacco) act 2002, 2002. Available: https://www.tobaccocontrollaws.org/legislation/country/ireland/ summary [Accessed 12 August 2020].

3 Frazer K, Callinan JE, McHugh J, et al. Legislative smoking bans for reducing harms from secondhand smoke exposure, smoking. Cochrane Database Syst Rev 2016;5:CD011856.

4 Wilson LM, Avila Tang E, Chander G, et al. Impact of tobacco control interventions on smoking initiation, cessation, and prevalence: a systematic review. J Environ Public Health 2012;2012:1-36.

5 Stallings-Smith S, Zeka A, Goodman P, et al. Reductions in cardiovascular, cerebrovascular, and respiratory mortality following the National Irish smoking ban: interrupted time-series analysis. PLoS One 2013;8:e62063.

6 World Health Organization. European tobacco use, trends report, 2019. Available: https://www.euro.who.int/en/health-topics/diseaseprevention/tobacco/publications/2019/european-tobacco-usetrends-report-2019-2019

7 Li S, Keogan S, Taylor K, et al. Decline of adolescent smoking in Ireland 1995-2015: trend analysis and associated factors. BMJ Open 2018;8:e020708.

8 Dunlop S, Kite J, Grunseit AC, et al. Out of sight and out of mind? evaluating the impact of point-of-sale tobacco display bans on smoking-related beliefs and behaviors in a sample of Australian adolescents and young adults. Nicotine Tob Res 2015;17:761-8.

9 Kraus L, Håkan L, Guttormsson U. Results from the European school survey project on alcohol and other drugs, 2015.

10 Hibell B, Ulf Guttormsson SA. Olga Balakireva, Thoroddur Bjarnason, Anna Kokkevi LK. The 2007 ESPAD report; substance use among students in 35 European countries, 2009. Available: www.espad.org

11 Hibell B, Guttormsson U, Ahlström S. The 2011 ESPAD report: substance use among students in 36 European countries, 2012.

12 Hibell B, Andersson B, Bjarnason T. The ESPAD report 2003 : alcohool and other drug use among students in 35 European countries, 2004.
13 Hibell B, Andersson B, Ahlström S, et al. The 1999 ESPAD report: alcohol and other drug use among students in 30 European countries. Dublin, 2000. Available: http://www.espad.org/sites/espad. org/files/The_1999_ESPAD_report.pdf

14 Chaloupka FJ, Warner KE. Chapter 29 the economics of smoking. Handb Heal Econ 2000;1:1539-627.

15 Currie LT, Leon Roux J, Godfrey M, et al. Policy recommendations for tobacco taxation in the European Union integrated research findings from the PPACTE project, 2012. Available: http://www.tri.ie/uploads/ 3/1/3/6/31366051/ppacte_policy_recommendations_and_integrated_ report.pdf

16 Kraus L, Seitz N-N, Piontek D, et al. 'Are the times A-changin'? trends in adolescent substance use in Europe. Addiction 2018;113:1317-32.

17 Gallet CA, List JA. Cigarette demand: a meta-analysis of elasticities. Health Econ 2003;12:821-35.

18 Tauras JA, Huang J, Chaloupka FJ. Differential impact of tobacco control policies on youth sub-populations. Int $J$ Environ Res Public Health 2013;10:4306-22.

19 Currie LM, Blackman K, Clancy L, et al. The effect of tobacco control policies on smoking prevalence and smoking-attributable deaths in Ireland using the IrelandSS simulation model. Tob Control 2013;22:e25-32.

20 Tauras JA. Can public policy deter smoking escalation among young adults? J Policy Anal Manage 2005;24:771-84.

21 Wakefield MA, Chaloupka FJ, Kaufman NJ, et al. Effect of restrictions on smoking at home, at school, and in public places on teenage smoking: cross sectional study. BMJ 2000;321:333-7.

22 Farkas AJ, Gilpin EA, White MM, et al. Association between household and workplace smoking restrictions and adolescent smoking. JAMA 2000;284:717.

23 Fahy D, Trench B, Clancy L. Communicating contentious health policy: lessons from Ireland's workplace smoking ban. Health Promot Pract 2012;13:331-8.

24 McNeill A, Lewis S, Quinn C, et al. Evaluation of the removal of pointof-sale tobacco displays in Ireland. Tob Control 2011;20:137-43.

25 Van Hurck MM, Nuyts PAW, Monshouwer K, et al. Impact of removing point-of-sale tobacco displays on smoking behaviour among adolescents in Europe: a quasi-experimental study. Tob Control 2019;28:401-8.

26 Edwards R, Ajmal A, Healey B, et al. Impact of removing point-ofsale tobacco displays: data from a new Zealand youth survey. Tob Control 2017;26:392-8.

27 Babineau K, Clancy L. Young people's perceptions of tobacco packaging: a comparison of EU Tobacco Products Directive \& Ireland's Standardisation of Tobacco Act. BMJ Open 2015;5:e007352.

28 Evans D, Farrell AO HP. Roll your own cigarettes in Ireland key patterns and trends roll your own cigarettes in Ireland. Dublin, 2017. Available: https://www.drugsandalcohol.ie/27372/1/Roll-Your-OwnReport-2017.pdf 